\title{
Nacre-Inspired Black Phosphorus/Nanofibrillar Cellulose Composite Film with Enhanced Mechanical Properties and Superior Fire Resistance
}

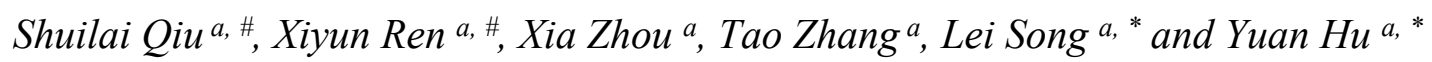

${ }^{a}$ State Key Laboratory of Fire Science, University of Science and Technology of China, 96 Jinzhai Road, Hefei, Anhui 230026, P.R. China

\section{Corresponding Authors}

*Yuan Hu. Fax/Tel: +86-551-63601664. E-mail: yuanhu@ustc.edu.cn

*Lei Song. Fax/Tel: +86-551-63600081. E-mail: leisong@ustc.edu.cn

\#: Joint first author, these authors contributed equally to this study 


\section{Characterization}

Fourier transform infrared (FTIR) spectra were performed by using a Nicolet 6700 spectrometer (Nicolet Instrument Co., USA).

X-ray diffraction (XRD) was employed on an X-ray diffractometer (Rigaku Co., Japan).

Transmission electron microscopy (TEM) (JEM-2100F, Japan Electron Optics Laboratory Co., Ltd., Japan) was conducted to study the morphology of BP-OH.

Atomic force microscopy (AFM) was carried out using a Dimension Icon (Bruker Nano Inc.) to characterize the size and thickness of exfoliated BP nanosheets.

X-Ray photoelectron spectroscopy (XPS) was used on a VG ESCALAB MK-II electron spectrometer (V.G. Scientific Ltd., UK) to investigate the chemical composition and valence states materials.

Raman spectra were collected on a Laser microRaman spectrometer (Jobin Yvon Co., Ltd., France) to study the structure components of BP-OH.

Thermogravimetric analysis (TGA) was performed by using a Q5000 thermo-analyzer instrument (TA Instruments Inc., USA) under nitrogen atmosphere at a linear heating rate of $20{ }^{\circ} \mathrm{C} \mathrm{min}-1$ from 50 to $800{ }^{\circ} \mathrm{C}$. 
The combustion properties were evaluated by a microscale combustion calorimeter (MCC) with an instrument model of Govmark MCC-2 (The Govmark Organization, Farmingdale, NY). Approximately $2-5 \mathrm{mg}$ of sample was heated in an inert gas atmosphere at a heating rate of $1 \mathrm{~K} \cdot \mathrm{s}^{-1}$, then the pyrolysis volatiles with carrier gases (nitrogen of $80 \mathrm{~mL} \cdot \min ^{-1}$; oxygen of $20 \mathrm{~mL} \cdot \min ^{-1}$ ) were mixed and burned at $900{ }^{\circ} \mathrm{C}$ in a combustion chamber. Recording the heat of combustion depends on the principle of oxygen consumption.

Scanning electron microscopy (SEM, JEOL JSM-6700) was taken to study fracture surface and microstructures of BP-OHx/NFC composite films.

The mechanical property of tensile strength was measured on an MTS CMT6104 universal testing machine (MTS Systems Co. Ltd., P.R. China) according to the Chinese standard of GB $13022-91$. The stretching rate was $20 \mathrm{~mm} \cdot \mathrm{min}^{-1}$. Each specimen was repeated for five times.

Dynamic mechanical analysis (DMA) was conducted with the PerkinElmer Pyris Diamond DMA from room temperature to $300^{\circ} \mathrm{C}$ at a linear heating rate of $5{ }^{\circ} \mathrm{C} / \mathrm{min}$, at a frequency of $1 \mathrm{~Hz}$ in the tensile configuration.

Water contact angle was measured by a digital goniometer DSA 100 (KRUSS GmbH, Germany) with $2 \mu \mathrm{L}$ of deionized water on samples of size $1 \times 1 \mathrm{~cm}^{2}$ at room temperature. The contact angle was measured within $0-15 \mathrm{~s}$ during the addition of water 
drop and the results and snap shots were recorded at $0 \mathrm{~s}$. For each sample three spots were performed.

Water stability of BP-OHx/NFC films was tested as following: dried film pieces $6 \mathrm{~mm}$ in diameter were weighted to $0.001 \mathrm{mg}$ for the initial dry weight (Wo). After that, films were immersed in $10 \mathrm{ml}$ distilled water at room temperature for $24 \mathrm{~h}$ and the wet weight (Ww) of samples were measured immediately. Then those films were dried under vacuum at $60{ }^{\circ} \mathrm{C}$ and weighted for final dry weight (Wd). The film water stability (Ws) and water absorbing capacity (Wa) were calculated as below ${ }^{1-2}$ :

$$
\begin{aligned}
& W s(\%)=\frac{(W o-W d)}{W d} \times 100 \% \\
& W a(\%)=\frac{(W w-W d)}{W d} \times 100 \%
\end{aligned}
$$




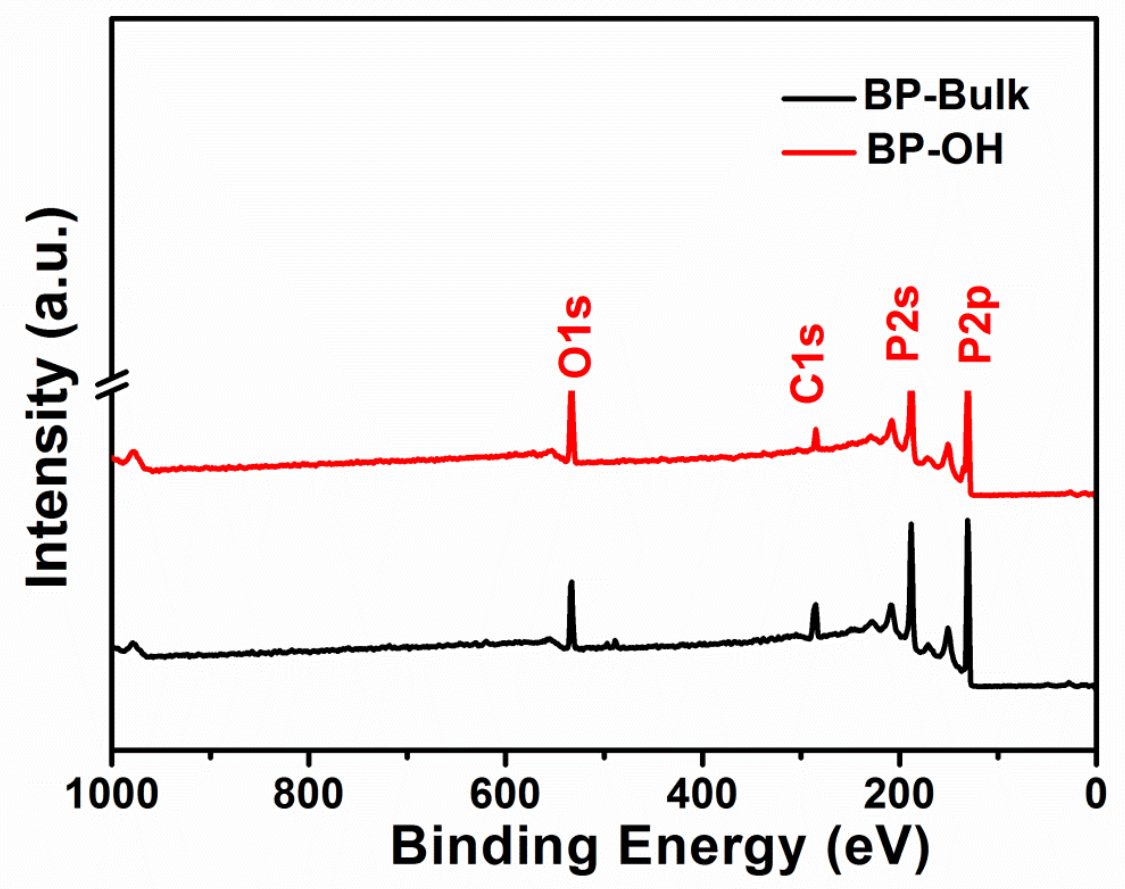

Figure S1. XPS survey spectra of the BP-Bulk and BP-OH. 


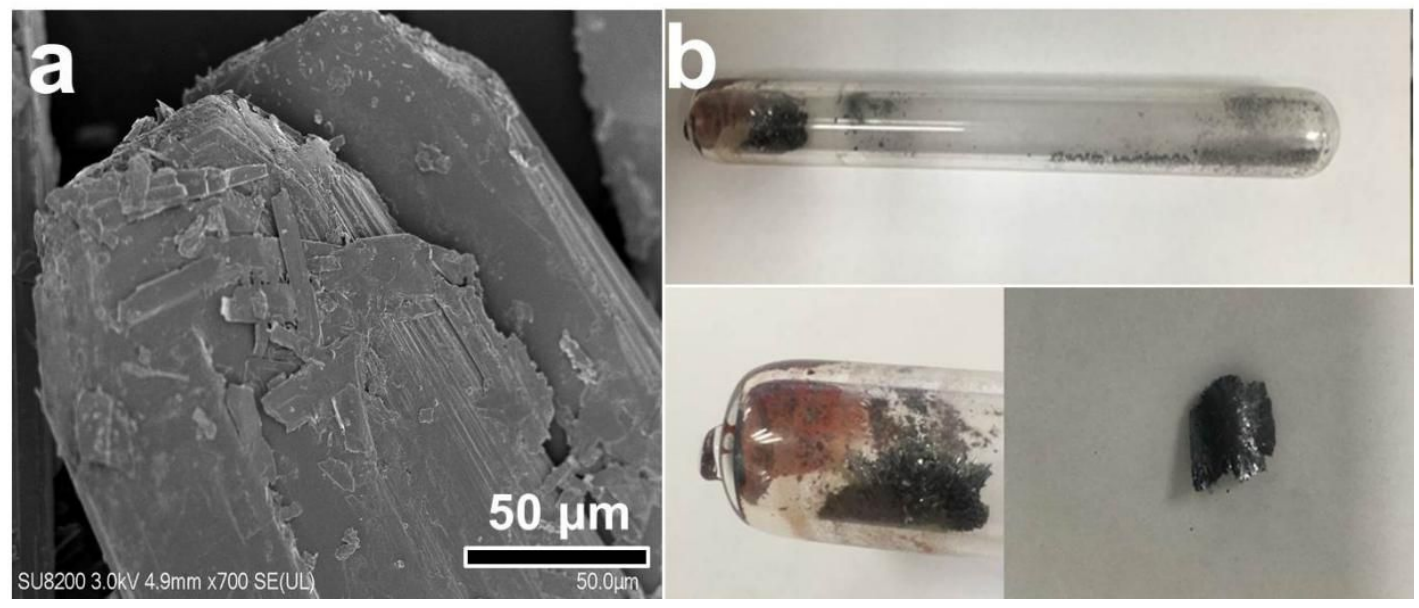

Figure S2. (a) SEM image of BP crystal; (b) Digital images of BP crystal. 


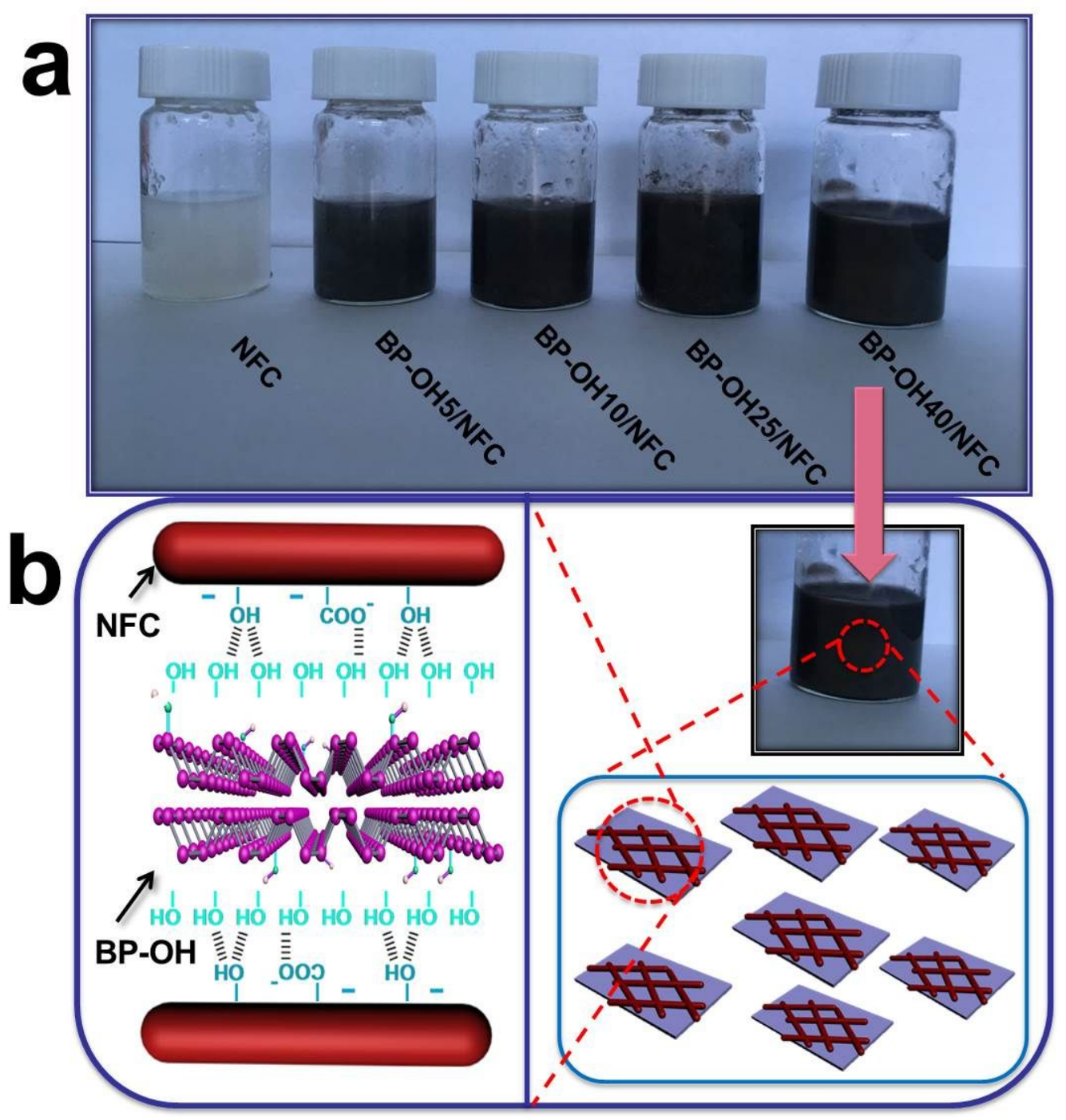

Figure S3. (a) Digital image of BP-OHx/NFC suspension; (b) Schematic illustration of the interaction between BP-OH and NFC by hydrogen bonds. 


\section{Hydrophilic characteristics of BP-OHx/NFC nanocomposite films}

The surface wettability of NFC film and its binary nanocomposite films were evaluated through water contact angle (CA) method by dripping a drop of water on the upper surface of film. The CA were obtained by averaging the left side angle and the right side angle. As shown in Figure S4, with the increasing of BP-OH content, larger CA were observed, indicating the decreased hydrophilic property of $\mathrm{BP}-\mathrm{OHx} / \mathrm{NFC}$ nanocomposite films. It's mainly because of the adding of BP-OH and increase of surface roughness ${ }^{3}$.

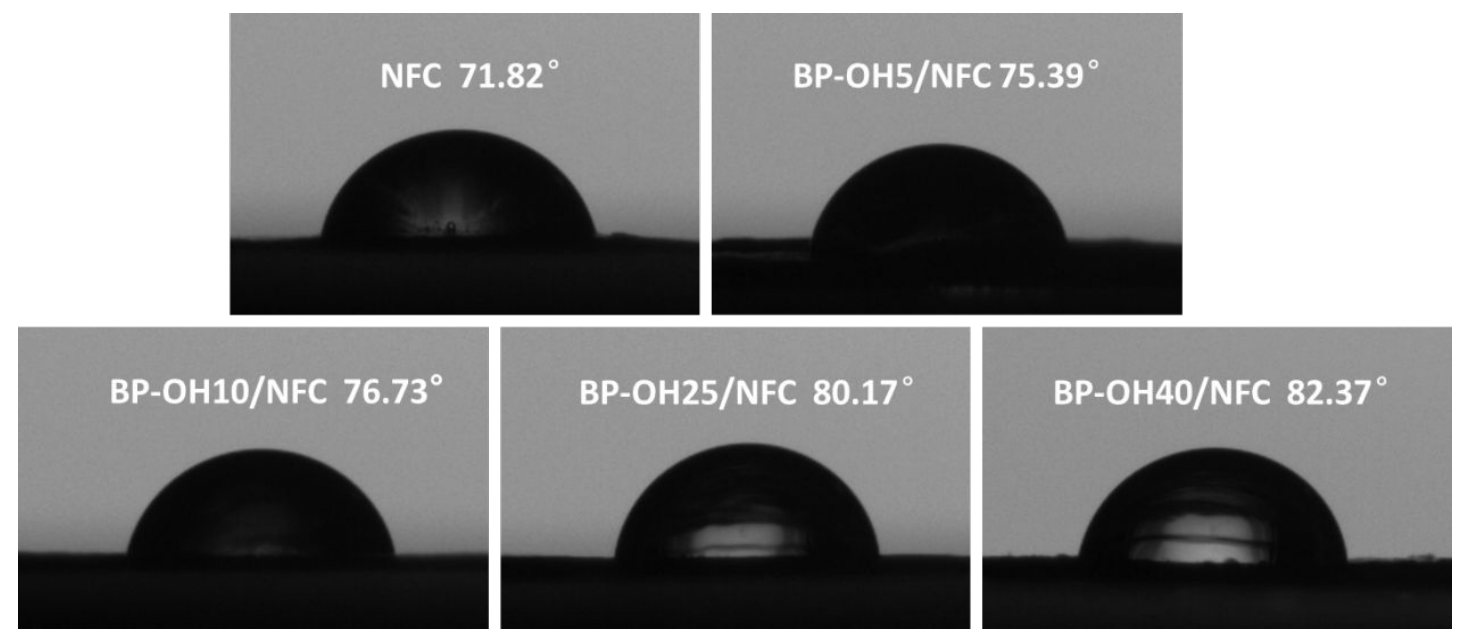

Figure S4. Contact angles of BP-OHx/NFC nanocomposite films 


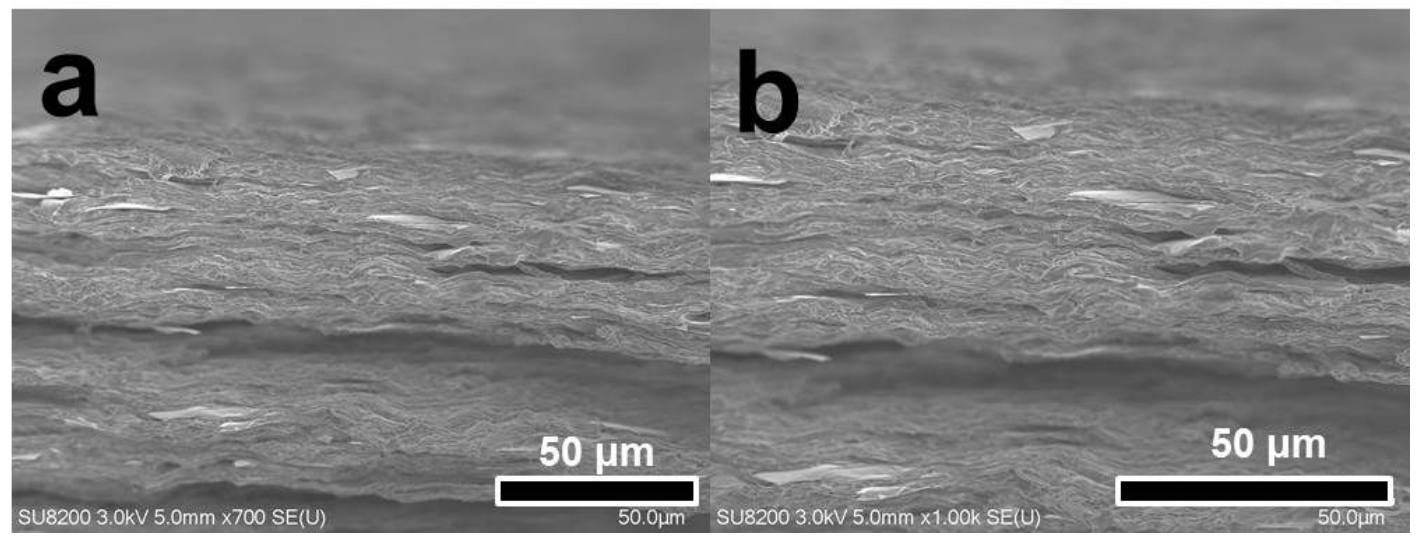

Figure S5. SEM images of the BP-OH5/NFC composite film in different magnification, exhibiting a nacre-like compact lamellar structure. 


\section{Air stability of BP-OHx/NFC nanocomposite films}

To evaluate the air stability of $\mathrm{BP}-\mathrm{OHx} / \mathrm{NFC}$ nanocomposite films, after exposure under atmospheric conditions for four months, the microstructure of fracture surface of BP-OH25/NFC sample was investigated by SEM. The composite papers have ordered lamellar structure as shown in Figure S6a, which is similar to the "brick-and-mortar" structure of nacre, meanwhile the "pull-out" BP nanosheets can be clearly observed. Figure S6b-e show the SEM image of BP-OH25/NFC composite film and corresponding elemental mapping images of phosphorus $(\mathrm{P})$, oxygen $(\mathrm{O})$, and carbon $(\mathrm{C})$. These results demonstrate that the $\mathrm{BP}-\mathrm{OH}$ nanosheets remained in $\mathrm{BP}-\mathrm{OH} / \mathrm{NFC}$ nanocomposite films exhibit good air stability.
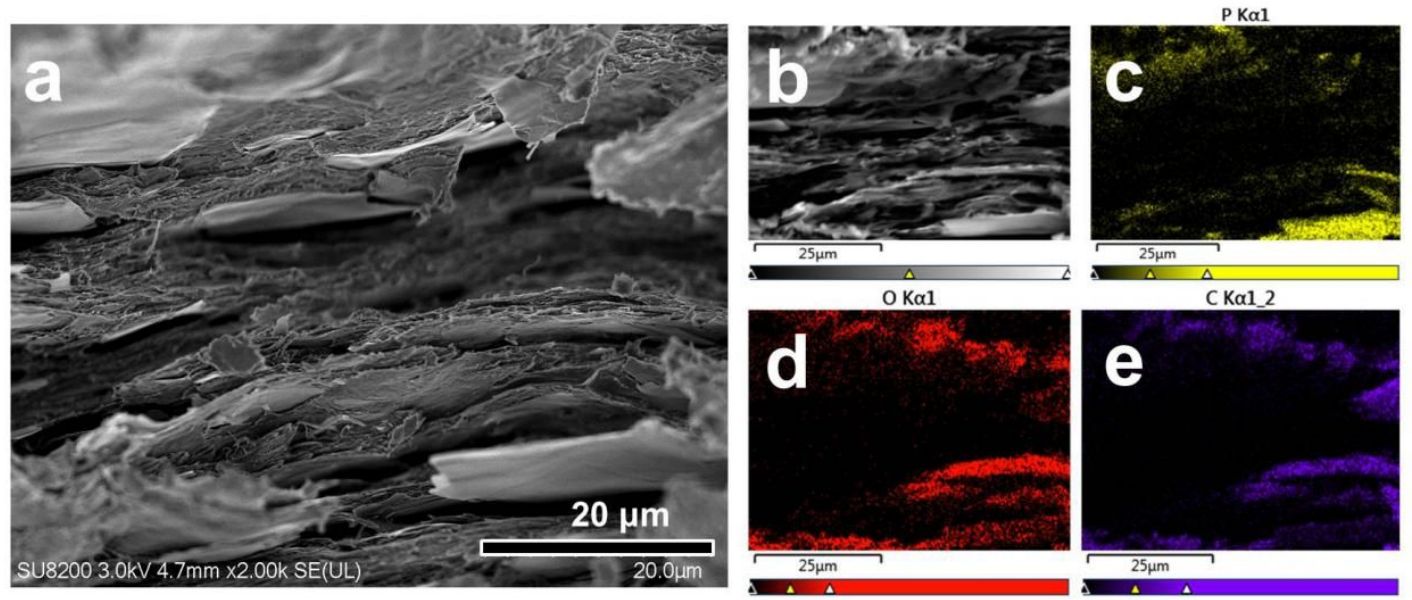

Figure S6. ( $a$ and $b$ ) The SEM image obtained from BP-OH25/NFC nanocomposite film and corresponding elemental mapping images of (c) phosphorus $(\mathrm{P}),(\mathrm{d})$ oxygen $(\mathrm{O})$ and (e) carbon (C) after exposure to ambient conditions for four months. 
These BP-OH25/NFC sample was further investigated by XRD pattern (Figure S7a) and Raman spectrum (Figure S7b). Its XRD pattern exhibits three intense diffraction peaks at $16.9^{\circ}, 34.2^{\circ}$ and 52.3 corresponding to the (020), (040), and (060) planes respectively, which are representative layered planes of BP. The diffraction peak at $2 \theta=$ $22.75^{\circ}$ corresponds to (002) crystal plane of cellulose crystalline structure. In Raman spectrum, three characteristic vibrational modes of BP crystal correspond to the peaks of $\mathrm{A}_{\mathrm{g}}{ }^{1}$ at $360.7 \mathrm{~cm}^{-1}, \mathrm{~B}_{2 \mathrm{~g}}$ at $438.6 \mathrm{~cm}^{-1}$, and $\mathrm{Ag}_{\mathrm{g}}{ }^{2}$ at $466.4 \mathrm{~cm}^{-1}$. The uniformly distributed crystalline BP nanosheets in BP-OH/NFC nanocomposites can be clearly seen by SEM images and elemental mapping images as shown in Figure S7c-e. These results further confirm that the $\mathrm{BP}-\mathrm{OH}$ in $\mathrm{BP}-\mathrm{OH} / \mathrm{NFC}$ nanocomposites with complete structure and crystallinity and cannot be degraded even on prolonged exposure to the air more than four month. As a consequence, these characterizations validate that the $\mathrm{BP}-\mathrm{OH}$ nanosheets in BP-OH/NFC nanocomposite films exhibit good air stability. 

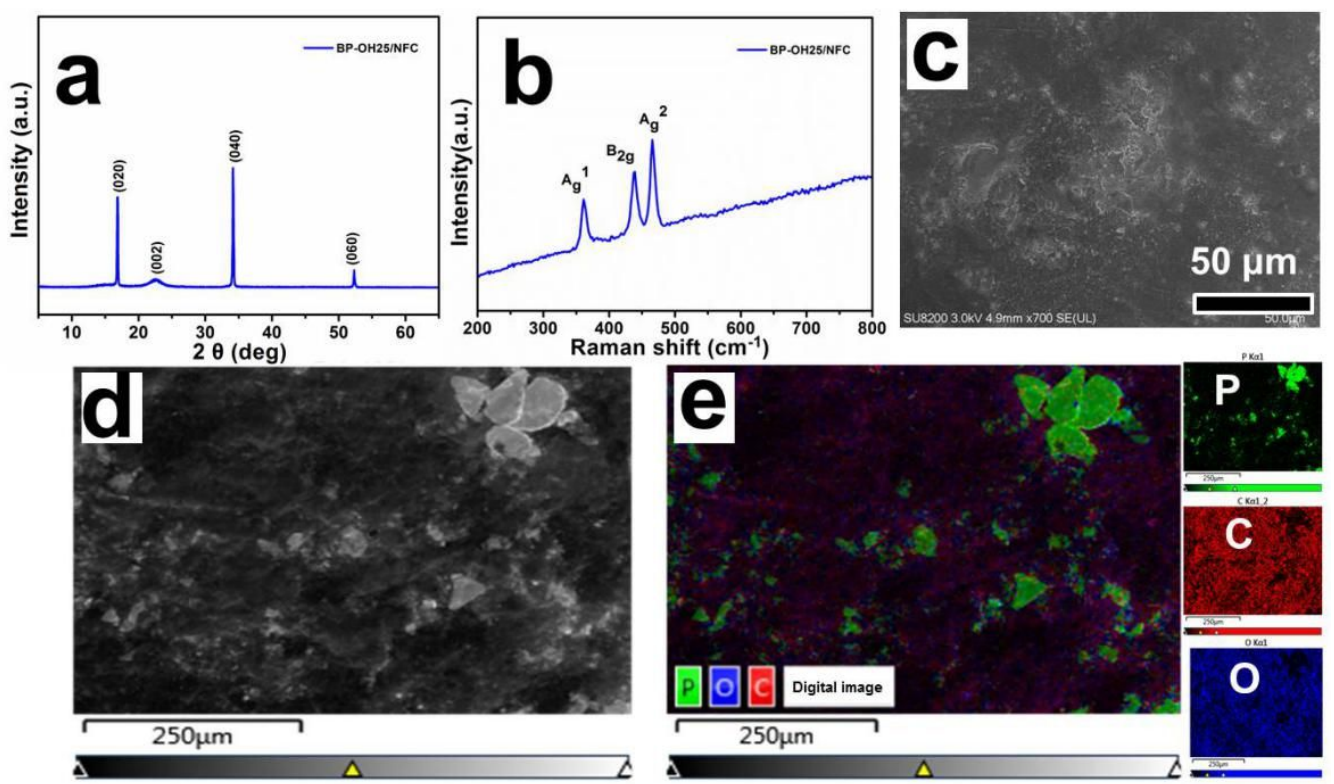

Figure S7. The corresponding (a) XRD pattern and (b) Raman spectrum of BP$\mathrm{OH} 25 / \mathrm{NFC}$ nanocomposite film after exposure to ambient conditions for four month; (c and d) The SEM images obtained from the surface of BP-OH25/NFC nanocomposite film and corresponding (e) elemental mapping images of phosphorus $(\mathrm{P})$, oxygen $(\mathrm{O})$ and carbon (C) after exposure to ambient conditions for four month, the well-dispersed crystalline BP nanosheets in the BP-OH25/NFC nanocomposite film are observed, demonstrating an air stability of BP-OHx/NFC nanocomposites. 
The Young's modulus of BP-OHx/NFC films were shown in Figure S8, the Young's modulus of pure NFC is $2.52 \mathrm{GPa}$, the BP-OH10/NFC sample shows the highest Young's modulus among these samples, reaches $2.84 \mathrm{GPa}$.

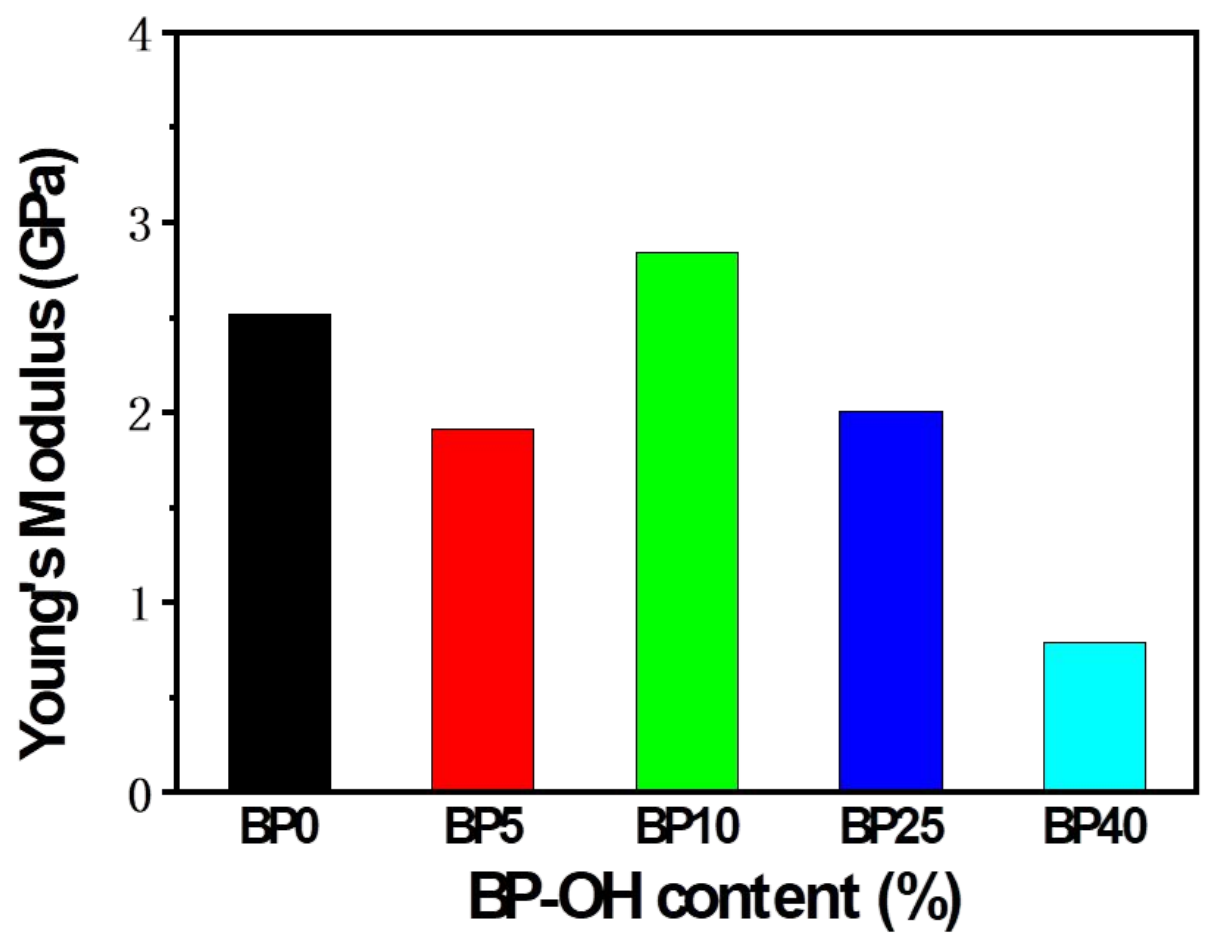

Figure S8. Young's modulus of BP-OHx/NFC films. 

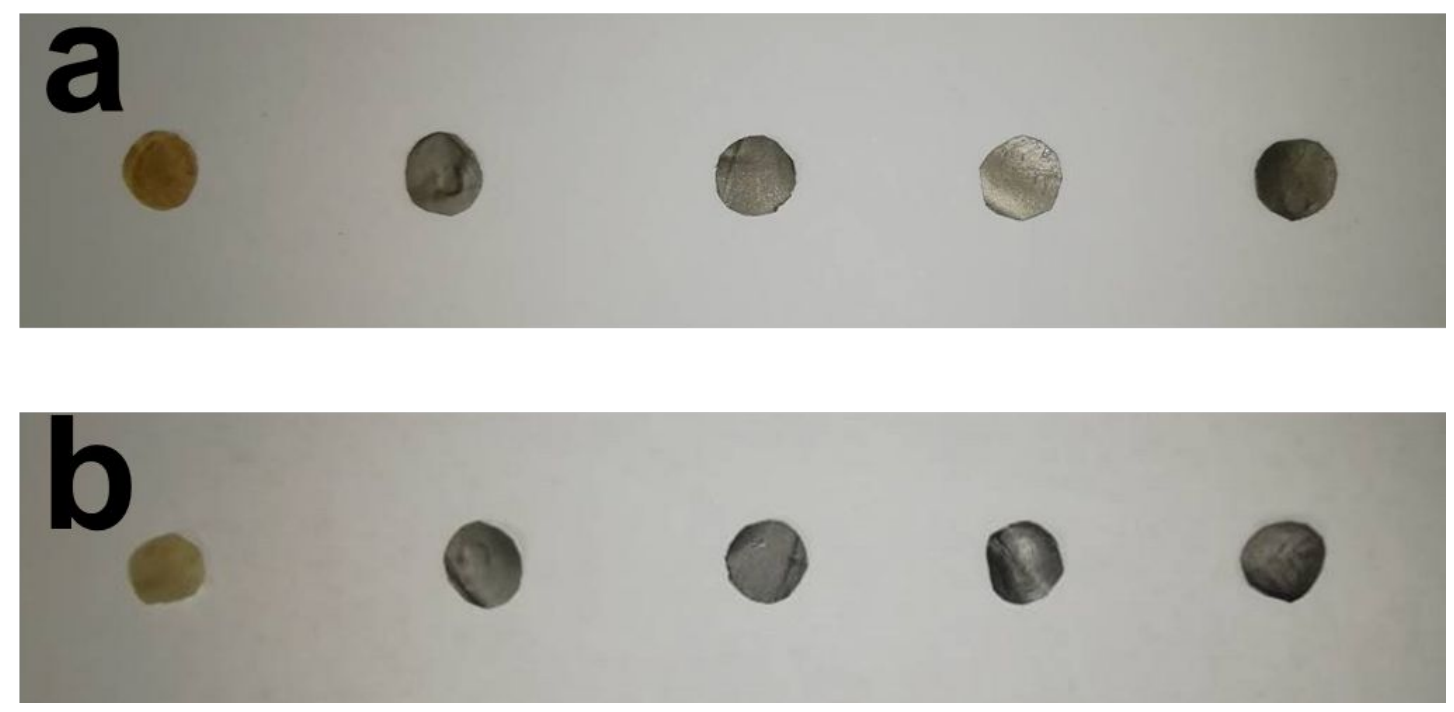

Figure S9. Optical images of BP-OHx/NFC films before (a) and after (b) immersing in water for 3 days. From left to right: NFC, BP-OH5/NFC, BP-OH10/NFC, BP-OH25/NFC, BP-OH40/NFC) 
Table S1. The comparison of mechanical properties of the natural nacre, the BP$\mathrm{OHx} / \mathrm{NFC}$ composite films, some nanofibrillar cellulose or bacterial cellulose based composite materials

\begin{tabular}{|c|c|c|c|c|}
\hline Sample & Materials & $\begin{array}{l}\text { Tensile strength } \\
(\mathrm{MPa})\end{array}$ & $\begin{array}{l}\text { Strain at fracture } \\
(\%)\end{array}$ & Reference \\
\hline 1 & NFC/MTM & 124 & $\sim 3$ & 4 \\
\hline 2 & Cellulose/MMT & 100 & $\sim 10$ & 5 \\
\hline 3 & CNF/graphene & 197.7 & 8.6 & 6 \\
\hline 4 & $\mathrm{~d}-\mathrm{Ti}_{3} \mathrm{C}_{2} \mathrm{~T}_{\mathrm{x}} / \mathrm{CNF}$ & 135.4 & 16.7 & 7 \\
\hline 5 & GNs/NFC-C & 61 & 2.1 & 8 \\
\hline 6 & DCC50-Talc50 & 135 & $\sim 5.5$ & 9 \\
\hline 7 & $\mathrm{NFC} / \mathrm{HEC}$ & 202 & 14 & 10 \\
\hline 8 & CACell/ACC/PAA & 169 & 4.5 & 11 \\
\hline 9 & Cellulose/GP/PPy & 90.8 & 10 & 12 \\
\hline 10 & $\mathrm{CS} / \mathrm{MMT} / \mathrm{CNF}$ & 61.19 & $\sim 5.2$ & 13 \\
\hline 11 & $\mathrm{CNF} / \mathrm{MHNP} / \mathrm{RC}$ & 214.4 & 18.5 & 14 \\
\hline 12 & $\mathrm{BC} /$ graphene & 230 & 5.9 & 15 \\
\hline 13 & $\mathrm{BC} / \mathrm{CMC}$ & 180 & 11.8 & 16 \\
\hline 14 & $\mathrm{PVA} / \mathrm{St} / \mathrm{BC}$ & 33.6 & 13.1 & 17 \\
\hline 15 & Nacre & 135 & 0.85 & 18 \\
\hline 16 & $\mathrm{BP}-\mathrm{OH} / \mathrm{NFC}$ & 214 & 23.8 & This work \\
\hline
\end{tabular}




\section{Supplementary References}

(1) Vatankhah, E.; Prabhakaran, M. P.; Jin, G.; Mobarakeh, L. G.; Ramakrishna, S. J. J. o. B. A. Development of nanofibrous cellulose acetate/gelatin skin substitutes for variety wound treatment applications. 2014, 28 (6), 909.

(2) Atila, D.; Keskin, D.; Science, A. T. J. M.; C, E. Crosslinked pullulan/cellulose acetate fibrous scaffolds for bone tissue engineering. 2016, 69 (dec.), 1103-1115.

(3) Rodionova, G.; Eriksen, Ø.; Gregersen, Ø. TEMPO-oxidized cellulose nanofiber films: effect of surface morphology on water resistance. Cellulose 2012, 19 (4), 1115-1123, DOI: 10.1007/s10570-012-9721-5.

(4) Liu, A. D.; Walther, A.; Ikkala, O.; Belova, L.; Berglund, L. A. Clay Nanopaper with Tough Cellulose Nanofiber Matrix for Fire Retardancy and Gas Barrier Functions. Biomacromolecules 2011, 12 (3), 633-641, DOI: 10.1021/bm101296z.

(5) Wang, Q. Y.; Guo, J. H.; Xu, D. F.; Cai, J.; Qiu, Y. T.; Ren, J. H.; Zhang, L. N. Facile construction of cellulose/montmorillonite nanocomposite biobased plastics with flame retardant and gas barrier properties. Cellulose 2015, 22 (6), 3799-3810, DOI: 10.1007/s 10570-015-0758-0.

(6) Zhang, T. P.; Zhang, X. F.; Chen, Y. W.; Duan, Y. X.; Zhang, J. M. Green Fabrication of Regenerated Cellulose/Graphene Films with Simultaneous Improvement 
of Strength and Toughness by Tailoring the Nanofiber Diameter. Acs Sustainable Chemistry \& Engineering 2018, $6 \quad$ (1), 1271-1278, DOI: 10.1021/acssuschemeng. $7 \mathrm{~b} 03608$.

(7) Cao, W. T.; Chen, F. F.; Zhu, Y. J.; Zhang, Y. G.; Jiang, Y. Y.; Ma, M. G.; Chen, F. Binary Strengthening and Toughening of MXene/Cellulose Nanofiber Composite Paper with Nacre-Inspired Structure and Superior Electromagnetic Interference Shielding Properties. Acs Nano 2018, 12 (5), 4583-4593, DOI: 10.1021/acsnano.8b00997.

(8) Yang, W. X.; Zhang, Y.; Liu, T. Y.; Huang, R.; Chai, S. G.; Chen, F.; Fu, Q. Completely Green Approach for the Preparation of Strong and Highly Conductive Graphene Composite Film by Using Nanocellulose as Dispersing Agent and Mechanical Compression. Acs Sustainable Chemistry \& Engineering 2017, 5 (10), 9102-9113, DOI: 10.1021/acssuschemeng.7b02012.

(9) Liimatainen, H.; Ezekiel, N.; Sliz, R.; Ohenoja, K.; Sirvio, J. A.; Berglund, L.; Hormi, O.; Niinimaki, J. High-Strength Nanocellulose-Talc Hybrid Barrier Films. Acs Applied Materials \& Interfaces 2013, 5 (24), 13412-13418, DOI: 10.1021/am4043273.

(10) Sehaqui, H.; Zhou, Q.; Berglund, L. A. Nanostructured biocomposites of high toughness-a wood cellulose nanofiber network in ductile hydroxyethylcellulose matrix. Soft Matter 2011, 7 (16), 7342-7350, DOI: 10.1039/c1sm05325f. 
(11) Saito, T.; Oaki, Y.; Nishimura, T.; Isogai, A.; Kato, T. Bioinspired stiff and flexible composites of nanocellulose-reinforced amorphous CaCO3. Materials Horizons 2014, $l$ (3), 321-325, DOI: 10.1039/c3mh00134b.

(12) Chen, J. H.; Xu, J. K.; Wang, K.; Qian, X. R.; Sun, R. C. Highly Thermostable, Flexible, and Conductive Films Prepared from Cellulose, Graphite, and Polypyrrole Nanoparticles. Acs Applied Materials \& Interfaces 2015, 7 (28), 15641-15648, DOI: 10.1021/acsami.5b04462.

(13) Li, J. L.; Zhou, M.; Cheng, G.; Cheng, F.; Lin, Y.; Zhu, P. X. Fabrication and characterization of starch-based nanocomposites reinforced with montmorillonite and cellulose nanofibers. Carbohydrate Polymers 2019, 210, 429-436, DOI: 10.1016/j.carbpol.2019.01.051.

(14) Zhao, J. Q.; Zhang, X. M.; Tu, R.; Lu, C. H.; He, X.; Zhang, W. Mechanically robust, flame-retardant and anti-bacterial nanocomposite films comprised of cellulose nanofibrils and magnesium hydroxide nanoplatelets in a regenerated cellulose matrix. Cellulose 2014, 21 (3), 1859-1872, DOI: 10.1007/s10570-014-0255-x.

(15) Feng, Y. Y.; Zhang, X. Q.; Shen, Y. T.; Yoshino, K.; Feng, W. A mechanically strong, flexible and conductive film based on bacterial cellulose/graphene nanocomposite. Carbohydrate Polymers 2012, 87 (1), 644-649, DOI: 10.1016/j.carbpol.2011.08.039. 
(16) Indrarti, L.; Indriyati; Syampurwadi, A.; Pujiastuti, S. Physical and Mechanical Properties of Modified Bacterial Cellulose Composite Films. In International Symposium on Frontier of Applied Physics; Rusydi, A.; Wicaksono, D. H. B.; Anggono, T.; Isnaeni; Herbani, Y.; Febriani, F.; Oemry, F.; Sudiro, T.; Izzuddin, H.; Birowosuto, M. D., Eds.; 2016.

(17) Chiulan, I.; Frone, A. N.; Panaitescu, D. M.; Nicolae, C. A.; Trusca, R. Surface properties, thermal, and mechanical characteristics of poly(vinyl alcohol)-starch-bacterial cellulose composite films. Journal of Applied Polymer Science 2018, 135 (6), DOI: 10.1002/app.45800.

(18) Jackson, A. P.; Vincent, J. F. V.; Turner, R. M. THE MECHANICAL DESIGN OF NACRE. Proceedings of the Royal Society Series B-Biological Sciences 1988, 234 (1277), 415-+, DOI: 10.1098/rspb.1988.0056. 